CLINICAL STUDY

\title{
Mortality in Cushing's syndrome: data from 386 patients from a single tertiary referral center
}

\author{
Maria Yaneva, Krassimir Kalinov ${ }^{1}$ and Sabina Zacharieva \\ Clinical Centre of Endocrinology, USHATE Acad. Ivan Penchev', Medical University, 2, Zdrave Street, Sofia 1431, Bulgaria and ${ }^{1}$ New Bulgarian \\ University, res. quarter Ovcha Kupel, 21, Montevideo Street, Sofia 1618, Bulgaria \\ (Correspondence should be addressed to S Zacharieva; Email: zacharieva@uheg.medicalnet-bg.org)
}

\begin{abstract}
Objective: Data on the incidence, mortality, and causes of death in patients with Cushing's syndrome (CS) are scarce, due to the rarity of CS. The aim of the study was to analyze mortality in a large cohort of patients of all etiologies and to determine the cause of death.

Design: This was a retrospective study of patients with CS, treated over a period of 45 years in the main tertiary referral center in Bulgaria.

Methods: Three hundred and eighty-six patients with CS of all etiologies were included. The main outcome measures were the standardized mortality ratio (SMR) and the cause of death.

Results: Mean ( \pm s.D.) age at diagnosis was $38 \pm 13$ years; $84 \%$ of patients were women; mean follow-up was 85 months (range: 0-494 months). The SMR in the CS cohort was 4.05 (95\% CI 2.50-5.80) $(P<0.0001)$. The following subgroups did not have a significantly increased SMR: patients with Cushing's disease SMR - 1.88 (95\% CI 0.69-4.08), adrenal adenomas 1.67 (95\% CI 0.20-6.02), and ACTH-independent bilateral adrenal hyperplasia 1.14 (95\% CI 0.21-6.34). Patients with adrenal carcinomas, ectopic CS, and those with CS of undetermined etiology had significantly increased SMR: 48.00 (95\% CI 30.75-71.42), 13.33 (95\% CI 0.00-24.59), and 4.00 (95\% CI $0.48-14.45$ ) respectively $(P<0.0001)$. The significant predictors for mortality were active disease at death, age, male sex, etiology of the disease, and the overall duration of active disease. The major causes of death were vascular events (40\%) - cardiovascular 29\%, and cerebrovascular 11\% - followed by infections (12\%). Conclusions: Patients with CS have increased mortality due to vascular events and infections.
\end{abstract}

European Journal of Endocrinology 169 621-627

\section{Introduction}

Cushing's syndrome (CS) is a rare condition that has a significant long-term impact on patients' physical and mental welfare. Recent studies on the epidemiology of the disease have demonstrated its low incidence (1.4-2.7/million per year) $(1,2,3,4,5)$ and a mean standardized mortality ratio (SMR), calculated on the basis of a meta-analysis, of 1.84 for patients with Cushing's disease (CD) and 1.90 for patients with adrenal adenomas (AA) (6). One study reported SMR data in patients with ectopic adrenocorticotrophic hormone (ACTH)-secretion and ACTH-independent adrenal hyperplasia (4); SMR data in patients with cortisol-secreting adrenal carcinomas have not been reported. Almost all mortality studies in CS have small patient numbers (49-289), which is attributable to the rarity of CS. Moreover, most studies focused only on CD. The aim of this study was to analyze mortality in CS patients in a large cohort of CS patients with different etiologies. To our knowledge, this study includes the largest number of patients treated in a single tertiary center for a significant period of time (45 years).
We performed a detailed analysis of the causes of death in our cohort of patients.

\section{Subjects and methods}

\section{Patients}

A total of 386 patients with proven CS, treated over a period of 45 years, were included. All patients were treated in the Clinical Center of Endocrinology at the Medical University of Sofia, Bulgaria, between 1965 and 2010. All data were obtained from the patients' medical records. As it was a retrospective audit study, no approval by the local ethics committee was required. The diagnosis of CS was based on the guidelines for diagnosis of the disease that were in force at that time. This varied depending on the time of diagnosis (elevated 17-OH and ketosteroids/elevated urinary free cortisol (UFC); lack of suppression after $2 / 1 \mathrm{mg}$ dexamethasone (DXM); and disrupted diurnal serum/salivary cortisol cycle). The differential diagnosis was confirmed on the basis of the basal and dynamic tests available at the 
moment of diagnosis - ACTH level, high dose DXM suppression test, corticotrophin-releasing hormone (CRH), or DDAVP desmopressin (1-desamino-8-Darginine vasopressin) tests. Plasma, salivary, and UFC assay kits used over time were different, so normal values of these hormones varied over time. Response to CRH or DDAVP was considered positive when ACTH rise was more than $50 \%$ and plasma cortisol rise was more than $25 \%$. Imaging methods were performed as follows: lateral skull X-ray (in very early cases), pituitary and adrenal CT/MRI scans, chest X-ray, thoracic or abdominal CT, and scintigraphy with octreoscan when needed. Patients with CS had surgery at a single specialized endocrine/pituitary surgery department by different dedicated surgeons, varying over time. Remission of CS was defined as clinical improvement after treatment (resolution of clinical symptoms), adrenal insufficiency with need for glucocorticoid replacement therapy, or normalization of the UFC (or urinary steroids in the early cases). In patients with $\mathrm{CD}$, initial remission after surgery was defined in the same way as that during the first postoperative checkout (1-3 months postoperatively). Cure of CS was defined as the absence of clinical and biochemical hypercortisolism (normal/low UFC or $17-\mathrm{OH}$ and ketosteroids in earlier cases and adequate cortisol suppression after $1 \mathrm{mg}$ DXM) at the last clinical visit. Patients with CD had transsphenoidal or transcranial surgery $(66 \%)$, radiotherapy $(6 \%)$, adrenal surgery $(22 \%)$, or medical treatment $(6 \%)$ as the first-line treatment, followed by adjuvant treatment when needed. The diagnosis of ectopic CS was based on clinical, hormonal, and pathohistological data. The etiology of patients with ectopic CS was as follows: two patients had a bronchial tumor, one had a pancreatic carcinoid tumor, two patients had a small-cell lung tumor, one had a pheochromocytoma with ectopic ACTH secretion, one had a thyroid medullary carcinoma, and five had occult ectopic ACTH secretion. Patients with ACTH-secreting tumors were operated upon and had histopathological confirmation of the diagnosis, while patients with occult ACTH secretion had bilateral adrenalectomy. All but two patients with cortisol-secreting adenomas were operated upon following histopathological confirmation of the disease. The two patients who had no surgery died with active disease (severe active disease that prevented them from undergoing major surgery). In total, 24/29 patients with adrenal carcinomas underwent surgery and had pathological confirmation of the disease. The other five patients had severe metastatic disease that did not permit surgery. For these cases, disease was confirmed pathologically at autopsy. In the group of patients with ACTH-independent hyperplasia $(n=11)$, six patients had adrenal surgery with histological confirmation. Another four patients refused surgery, and one patient with Carney complex (genetically confirmed) refused surgery, motivated by the cyclic course of the disease and chose medical treatment when needed.

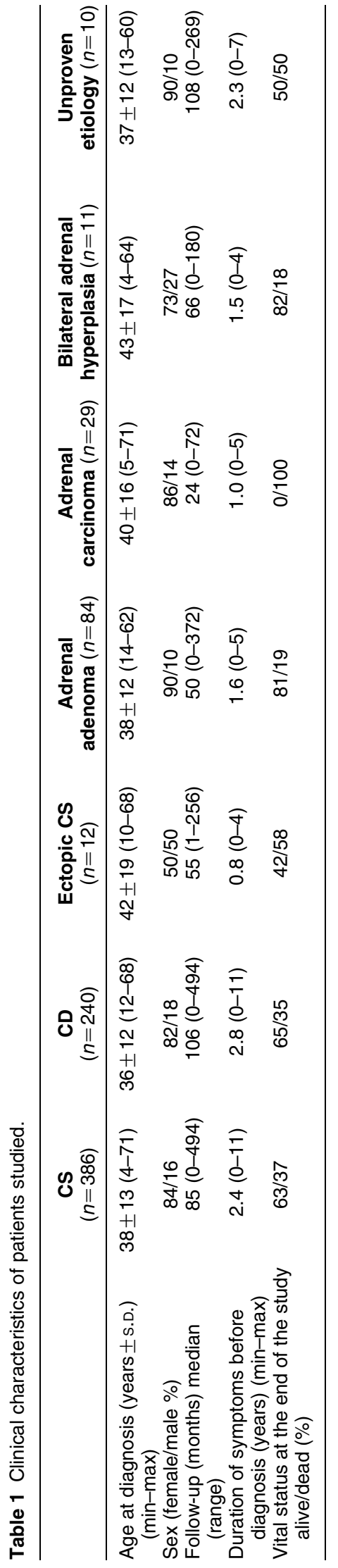




\section{Study methods}

This is a retrospective study. We analyzed the medical records of all patients from 1965 to 2010. The number of records for a single patient varied from 2 to 35 (with a mean of five records per patient, a total number of 2000 records were analyzed). Data on mortality were available in 360 patients' records. Data on mortality have been collected from patients' hospital records, autopsy records (if they died in hospital), reports of immediate family members, or on the basis of the National Statistical Institute (ESGRAON) from which we could obtain the data and the cause of death (coded with International Classification of Diseases, ICD-9, or 10, depending on the time of death).

\section{Statistical analysis}

The following statistical methods were used: standard one- and two-dimensional frequency distributions for non-metric parameters; number of observations $(n)$, arithmetic mean, s.D., and minimal and maximal values for metric variables. Cox regression analysis was used to assess the strength of relation between mortality and some specific influential factors. Student's $t$-test and $\chi^{2}$ test were used for statistical inferences where applicable. Significance level was fixed at 5\% everywhere. SMRs were calculated as the ratio between the observed and the expected number of deaths/per year. The expected number of deaths adjusted for age and sex was computed by multiplying age and sex mortality rates in the Bulgarian general population (official data may be found at http://www.nsi.bg/otrasal.php?otr=19) by the person-years at risk in corresponding age and sex strata in the cohort: $95 \%$ CIs and $P$ values for the SMR were exact (Poisson distribution). Kaplan-Meier model with plots was applied to estimate the probabilities for survival. The data analysis was performed by SAS version 9 (SAS Institute Inc., Cary, NC, USA).

\section{Results}

The clinical characteristics of all studied patients $(n=386)$ are presented in Table 1 . The distribution of patients included in the study over the years is presented in Fig. 1. All patients were treated at the Clinical Center of Endocrinology at the Medical University of Sofia. This tertiary referral center is the main center for treatment of pituitary diseases in the country, where almost 95\% of patients with CS in Bulgaria were managed. The incidence of CS, calculated on the basis of patients treated in this center, was estimated at $1.4 /$ million per year. Mean follow-up from the date of diagnosis to the last follow-up visit, or to the date of death, was $85 \pm 94$ months (mean \pm s.D.) (Table 1). Mean duration of symptoms ( \pm s.D.) before the diagnosis was $2.4 \pm 2.2$ years (Table 1). By the end of the study, $37 \%$ of studied

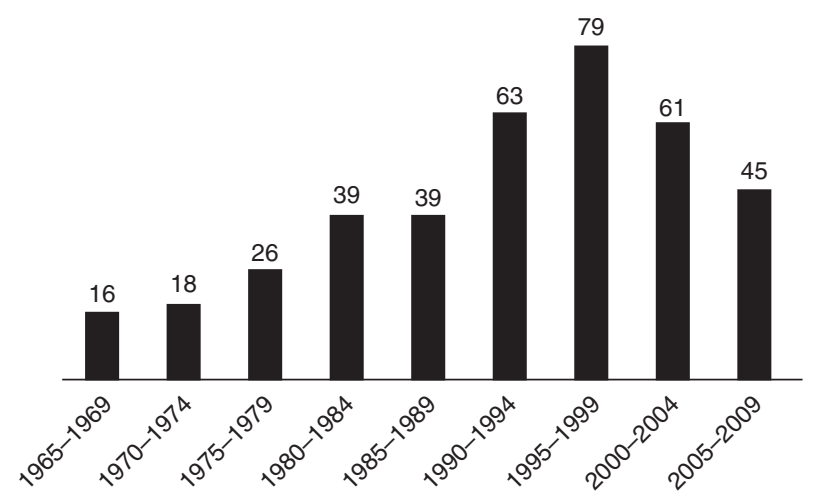

Figure 1 Number of patients included in the study over the years.

patients had died. The SMR data in the overall group and in the subgroups of patients with different CS etiologies are presented in Table 2. The SMR of the entire cohort of patients with CS was significantly increased $(P<0.0001)$. The SMR, in CS patients without adrenal carcinoma (AC), ectopic ACTH secretion, or undetermined origin, was 2.22 (95\% CI 1.06-4.08; $P=0.00973)$. Patients with $\mathrm{CD}$, AA or ACTH-independent adrenal nodular hyperplasia had SMR that did not differ significantly from the general population (Table 2). The Kaplan-Meier plots for survival over the years for the entire cohort of patients and for the different subgroups of patients are presented in Figs 2 and 3. The 5-, 10-, 15-, and 20-year survival rates of patients with benign $\mathrm{CS}$ were calculated as $89,84,80$ and $71 \%$ respectively.

Patients with CD $(n=240)$ underwent various treatment modalities: 154 (66\%) underwent transsphenoidal surgery (TSS) as the first-line treatment. In patients with initial remission after TSS (55\%), 86\% were alive at the end of the study compared with $59 \%$ of patients in whom no initial remission after pituitary surgery was ascertained. In the group of the patients treated with TSS alone or in combination with other additional treatments, $79 \%$ were considered as cured (remission) at the last follow-up. Six percent of the patients had radiotherapy alone. In this group, only $29 \%$ of the patients were alive at the end of the study. Another $6 \%$ of the patients had medical treatment only. Among them, 58\% were alive at the end of the study: $11 \%$ of the patients with CD underwent bilateral adrenalectomy, $11 \%$ had had unilateral adrenalectomy alone, or combined with other treatment modalities. At the end of the study, $46 \%$ of those treated with bilateral adrenalectomy and $50 \%$ of the patients who had unilateral adrenalectomy alone or in addition to other treatment were alive. Patients with CD, lost to endocrinology follow-up, had the poorest outcome only $17 \%$ were alive at the end of the study. Survival rates in patients with $\mathrm{CD}$ differed significantly according to the first-line treatment $(P=0.012)$. 
Table 2 Standardized mortality ratio (SMR) in patients with CS of different etiologies.

\begin{tabular}{|c|c|c|c|c|c|c|c|}
\hline & $n$ total & $\begin{array}{l}\text { Deaths } \\
\text { total }\end{array}$ & $\begin{array}{c}\text { Observed } \\
\text { deaths/year }\end{array}$ & $\begin{array}{c}\text { Expected } \\
\text { deaths/year }\end{array}$ & SMR & $95 \% \mathrm{Cl}$ & $P$ value \\
\hline Cushing's disease & 240 & 66 & 6 & 3.20 & 1.88 & $0.69-4.08$ & 0.1175 \\
\hline Ectopic CS & 12 & 7 & 2 & 0.15 & 13.33 & $0.00-24.59$ & $<0.0001$ \\
\hline Adrenal adenoma & 84 & 12 & 2 & 1.20 & 1.67 & $0.20-6.02$ & 0.4429 \\
\hline Adrenal carcinoma & 29 & $26^{a}$ & 24 & 0.5 & 48.00 & $\begin{array}{l}30.75- \\
71.42\end{array}$ & $<0.0001$ \\
\hline Bilateral adrenal hyperplasia & 11 & 2 & 2 & 1.75 & 1.14 & $0.21-6.34$ & 0.8501 \\
\hline Unproven etiology & 10 & 4 & 2 & 0.5 & 4.00 & $0.48-14.45$ & 0.0339 \\
\hline CS (all patients) & 386 & 117 & 21 & 5.19 & 4.05 & $2.50-5.80$ & $<0.0001$ \\
\hline
\end{tabular}

Values with statistical significance are in bold.

${ }^{a} 3 / 29$ patients with adrenal carcinoma were lost to follow-up.

In the group of patients with CS who died (37\%), the mean life span in patients with active hypercortisolism was 48.5 vs 55.1 years in patients in remission. Mean longevity of the Bulgarian population by 2010 was 73.6 years. Patients with ectopic CS had the poorest duration of life (from the establishment of the diagnosis to death) - mean 4.5 months, patients with adrenal carcinomas -18 months.

We found a significant correlation between sex and mortality rate $(P=0.03)$. The odds ratio $(\mathrm{OR}) \mathrm{male} /$ female was estimated at 1.93 (95\% CI 1.25-2.99). Age at diagnosis was correlated significantly with mortality $(P<0.0001)$ (OR 1.060; 95\% CI 1.04-1.77). The relation between mortality and overall duration of activity of symptoms was found to be significant $(P=0.001 ; \mathrm{OR}=0.992 ; 95 \%$ CI $(0.988 ; 0.997))$. The etiology of the disease, the current status at death (cured or active) correlated significantly with death $(P<0.0001)$. Cured patients had a 6.9-fold higher probability of being alive compared with active patients (OR 6.9; 95\% CI 4.72-10.12). The SMR of patients in remission was estimated at 1.67 (95\% CI $0.61-3.62)$. There was no significant difference in the mortality of the general population. By contrast, the SMR of active patients was $2.4(95 \%$ CI $0.87-8.19)(P=0.0139)$. Patients with CD without initial remission after TSA had a significantly higher mortality rate $(P=0.005)$ (OR 2.793; 95\% CI 1.367-5.705).

We completed a detailed analysis of the cause of death (Table 3). The major cause of death (29\% of the cases), regardless of the etiology, was cardiovascular disease. The second most frequent cause of death was infection and septic complications (12\%). Next came death from cerebrovascular disease $(11 \%)$. In patients with $\mathrm{CD}$, the most frequent cause of death was cardiovascular disease (32\%), followed by cerebrovascular disease (15\%), and infections (9\%). Patients with ectopic CS died most often from cardiovascular diseases (43\%), infections (29\%), and osteoporosis and its complications (14\%). Thromboembolic complications were the most frequent cause (19\%) of death in patients with cortisol-producing AAs, followed by infections (12.5\%), cerebrovascular diseases $(12.5 \%)$, and other neoplasms $(12.5 \%)$. For patients with cortisol-secreting ACs, the most frequent causes of death were cardiovascular diseases and infection/sepsis (24 and 21\%). In the groups of patients with ACTHindependent bilateral adrenal hyperplasia and CS with undetermined origin, analysis on the cause of mortality was not assessed because of the very low number of patients and deaths in each group.

\section{Discussion}

The main advantage of this study is the relatively large number of patients included $(n=386)$, treated in a single tertiary clinical center, compared with other studies of the same topic. The characteristics of our cohort (age and sex distribution) were similar to those of other studies. The follow-up of our patients is one of the longest. Although we have a subsequent number of patients followed from the 1960s, the inclusion of patients with a potentially lethal course of the disease (such as patients with $\mathrm{AC}$ and ectopic CS), with very brief follow-up, led to the shortening of the overall follow-up of our cohort of patients. We found that

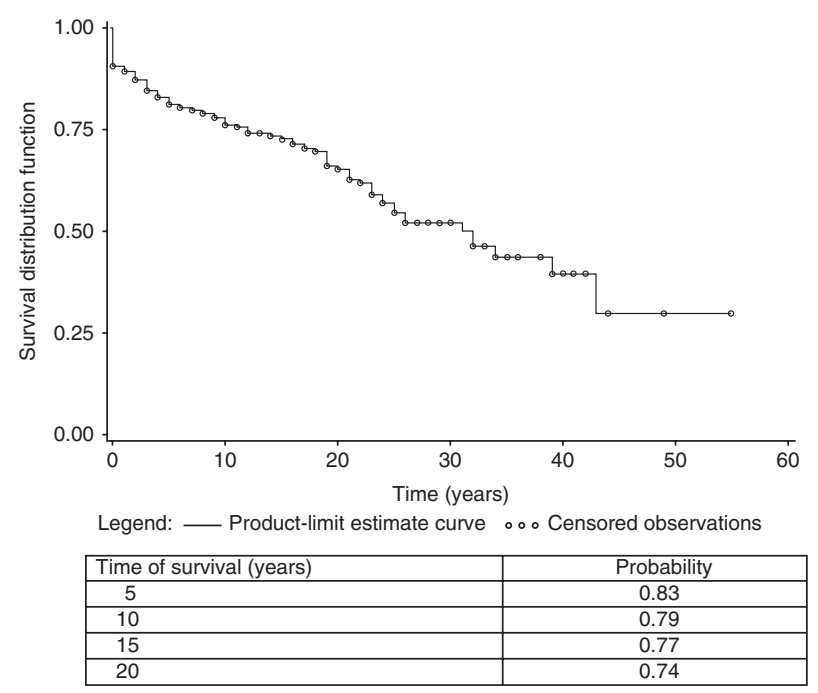

Figure 2 Kaplan-Meier survival plot: all patients with CS over the years. The table below the figure shows the probability for survival of a definite period of time. 


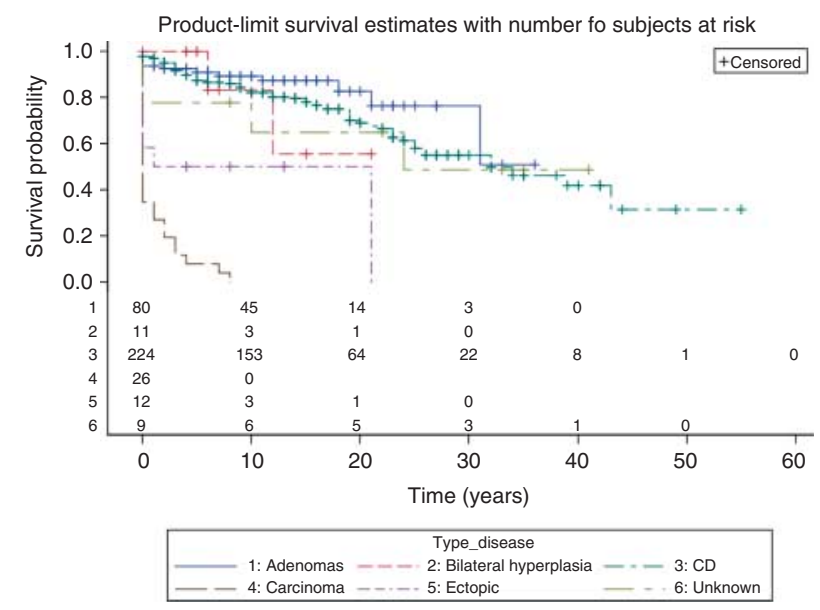

Figure 3 Kaplan-Meier survival plot: patients with CS of different etiologies over the years.

patients with CS have significantly increased mortality (SMR: 4.05; 95\% CI 2.5-5.8) compared with the general population $(P<0.0001)$. This mirrors the findings of Bolland et al (4) who reported an SMR of 4.1 , based on a somewhat smaller total population $(n=253)$ that excluded patients with AC.

Our data demonstrate that the 5-, 10-, 15-, and 20 -year survival rates were $83,79,77,74 \%$ respectively (Fig. 2), thus confirming how radically survival periods in CS have changed over the previous 60 years since the data of Plotz et al. in the 1950s and particularly since the data from Harvey Cushing himself when the mean survival period was only 4.7 years $(7,8)$.

We found that the most significant predictor for mortality was disease activity status (active vs cured). Cured patients had 6.9-fold higher probability to survive compared with patients with active disease. Patients in remission have no increased mortality compared with the general population. By contrast, patients with active disease had a significantly higher mortality rate than the general population. These results are in line with other large studies $(1,9,10)$, while other works in small patient cohorts (albeit with longer follow-up) show the opposite results $(5,11)$. Although it has been demonstrated that increased cardiovascular risk persists even in patients with $\mathrm{CD}$ in remission, this risk factor is probably manifested in very long follow-up, and our data suggest that this is evident particularly in ACTHdependent disease. Besides the activity of the disease, another adverse predictor for mortality was the male sex and the overall duration of the activity of the disease. Very few predictors for mortality in CS patients have been identified in the literature: older age at diagnosis (2), persistent hypercortisolism after initial surgery $(1,9)$, biochemical cure at last follow-up, and hypertension at last follow-up (4).

The other major advantage of our study is the assessment of the SMR of all etiologies of CS. To the best of our knowledge, there are no data on mortality in AC, whereas data concerning patients with other causes of ACTH-independent CS are scarce.

As might be expected, patients with cortisol-secreting adrenal carcinomas have the poorest survival rate (SMR of 48.00, $P<0.0001$ ), with a mean survival from the time of diagnosis of 18 months.

Patients with cortisol-secreting adenomas have no increased mortality (SMR 1.67, $P=0.4429$ ). A metaanalysis on the mortality in CS (based on the data of 109 patients with cortisol-secreting AA from three studies) revealed a similar SMR of 1.90 (95\% CI 0.93-3.91), thus confirming the relatively benign course of this etiology (6). In a smaller cohort of patients with AA $(n=37)$, Bolland et al. (4) found a significantly high SMR of 7.5 (95\% CI 1.9-20), attributed to a high perioperative mortality, but no deaths occurred subsequently during the postoperative follow-up (Table 4).

In our series, patients with ACTH-independent adrenal hyperplasia have no significant increase in the SMR of 1.14 (95\% CI 0.21-6.34). The mortality in this specific subset of patients has been addressed in only

Table 3 Cause of death in patients with Cushing's syndrome.

\begin{tabular}{|c|c|c|c|c|c|}
\hline & Total (\%) & $\begin{array}{c}\text { Cushing's } \\
\text { disease (\%) }\end{array}$ & $\begin{array}{l}\text { Ectopic } \\
\text { CS (\%) }\end{array}$ & Adenoma (\%) & Carcinoma (\%) \\
\hline Cardiovascular diseases $^{1}$ & 29 & 32 & 43 & 0 & 24 \\
\hline Infections and sepsis ${ }^{2}$ & 12 & 9 & 29 & 12.5 & 21 \\
\hline Cushing's syndrome ${ }^{3}$ & 12 & 5.1 & 0 & 0 & 45 \\
\hline Cerebrovascular diseases ${ }^{4}$ & 11 & 15 & 0 & 12.5 & 3.4 \\
\hline Other neoplasms ${ }^{5}$ & 6 & 7.7 & 0 & 12.5 & 0 \\
\hline Diabetes mellitus and complications ${ }^{6}$ & 4.4 & 6.4 & 0 & 6 & 0 \\
\hline Thromboembolism ${ }^{7}$ & 3.6 & 1.3 & 0 & 19 & 0 \\
\hline Traumas $^{8}$ & 1.5 & 2.6 & 0 & 0 & 0 \\
\hline Acute renal failure ${ }^{9}$ & 1.5 & 1.3 & 0 & 6 & 0 \\
\hline Hepatic failure ${ }^{10}$ & 0.7 & 1.3 & 0 & 0 & 0 \\
\hline Osteoporosis ${ }^{11}$ & 0.7 & 0 & 14 & 0 & 0 \\
\hline Others $^{12}$ & 0.7 & 1.3 & 0 & 0 & 0 \\
\hline Undetermined cause & 16 & 16.7 & 14 & 31 & 7 \\
\hline
\end{tabular}

The three most frequent causes of death for each etiology are in bold. ICD-10: ${ }^{1}(\mathrm{I11}, \mathrm{I20}, \mathrm{I21}, \mathrm{I25}, \mathrm{I46}, \mathrm{I50}) ;{ }^{2}(\mathrm{~J} 18, \mathrm{~K} 65, \mathrm{L08}, \mathrm{A} 41) ;{ }^{3}(\mathrm{E} 24, \mathrm{C} 74) ;{ }^{4}(\mathrm{I} 161, \mathrm{I63}, \mathrm{I64})$, ${ }^{5}(\mathrm{C} 19-21, \mathrm{C} 22, \mathrm{C} 25, \mathrm{C} 34, \mathrm{C} 53, \mathrm{C} 56, \mathrm{C} 64, \mathrm{C} 71, \mathrm{C} 73),{ }^{6}(\mathrm{E} 10, \mathrm{E} 11),{ }^{7}(\mathrm{I} 26, \mathrm{I74}, \mathrm{I80}),{ }^{8}(\mathrm{~S} 01, \mathrm{~S} 02),{ }^{9}(\mathrm{~N} 17, \mathrm{~N} 19),{ }^{10}$ (K72, K76), ${ }^{11}$ (M80-82), ${ }^{12}$ (N99, E07). 
Table 4 Mortality in CS (summary of data of all studies, analyzing SMR in CS).

\begin{tabular}{|c|c|c|c|c|c|c|c|}
\hline Study & $\begin{array}{c}\text { No. of } \\
\text { patients }\end{array}$ & Etiology & $\begin{array}{l}\text { Study } \\
\text { period }\end{array}$ & $\begin{array}{l}\text { Follow-up (months) } \\
\text { median (range) }\end{array}$ & SMR & $95 \% \mathrm{Cl}$ & $\begin{array}{c}\text { Significance } \\
(P)\end{array}$ \\
\hline (2) & 49 & $\mathrm{CD}$ & $1975-1992$ & $56(6-210)$ & 3.8 & $2.5-17.9$ & $<0.05$ \\
\hline (14) & 159 & CD & 1978-1996 & $96(12-240)$ & 0.98 & $0.44-2.2$ & NS \\
\hline \multirow[t]{5}{*}{ (13) } & 74 & Entire cohort & 1981-1994 & $89(0-180)$ & 1.68 & $0.81-30.9$ & NS \\
\hline & & $\mathrm{CD}(n=43)$ & & & 2.67 & $0.89-5.3$ & NS \\
\hline & & $\mathrm{AA}(n=20)$ & & & 1.35 & $0.16-4.9$ & NS \\
\hline & & $\begin{array}{l}\text { ACC }(n=4), \\
\text { ectopic }(n=4) \text {, }\end{array}$ & & & & & \\
\hline & & $\begin{array}{l}\mathrm{BNH}^{\mathrm{a}}(n=2), \\
\text { unclear }(n=1)\end{array}$ & & & & & \\
\hline \multirow[t]{4}{*}{ (1) } & 110 & Entire cohort & 1985-1995 & $96(36-168)$ & 3.68 & $2.34-5.33$ & \\
\hline & & $\mathrm{CD}(n=73)$ & & & 1.7 & $0.7-3.5$ & NS \\
\hline & & $\begin{array}{l}\text { CD, unproven } \\
(n=26)\end{array}$ & & & 11.48 & $5.73-20.5$ & $<0.001$ \\
\hline & & $\mathrm{AA}(n=37)$ & & & 3.48 & $0.95-8.9$ & 0.04 \\
\hline (9) & 289 & $C D$ & $1975-1998$ & $132(6-288)$ & 1.42 & $0.95-2.1$ & \\
\hline (16) & 50 & AA & $1980-2000$ & $134(13-264)$ & & & NS \\
\hline (10) & 74 & CD & 1977-2005 & $120(36-204)$ & 2.39 & $1.2-3.9$ & $<0.05$ \\
\hline (5) & 60 & $C D$ & $1958-2010$ & $180(6-492)$ & 4.8 & $2.8-8.3$ & $<0.0001$ \\
\hline \multirow[t]{7}{*}{ (4) } & 253 & Entire cohort & 1960-2005 & $77(0-552)$ & 4.1 & $2.9-5.6$ & $<0.001$ \\
\hline & & $\mathrm{AA}(n=37)$ & & & 7.5 & $1.9-20$ & 0.009 \\
\hline & & $\mathrm{BNH}(n=9)$ & & & 14 & $3.7-40$ & 0.001 \\
\hline & & $\begin{array}{l}\text { Pit macroadenoma } \\
\qquad(n=30)\end{array}$ & & & 3.5 & $1.3-7.8$ & 0.018 \\
\hline & & $\begin{array}{l}\text { Pit microadenoma } \\
\quad(n=158)\end{array}$ & & & 3.2 & $2.0-4.8$ & $<0.001$ \\
\hline & & $\begin{array}{l}\text { Occult ectopic } \\
\quad(n=10)\end{array}$ & & & 27 & $8.5-65$ & $<0.001$ \\
\hline & & $\begin{array}{l}\text { Probable ectopic } \\
\quad(n=9)\end{array}$ & & & 3.1 & $0.5-10$ & 0.16 \\
\hline$(11)$ & 80 & CD & 1988-2009 & $132(59-187)$ & 3.17 & $1.7-5.43$ & $<0.001$ \\
\hline \multirow{7}{*}{$\begin{array}{l}\text { Yaneva, } 2013 \\
\text { (present } \\
\text { study) }\end{array}$} & 386 & Entire cohort & $1965-2010$ & $85(0-494)$ & 4.05 & $2.5-5.8$ & $<0.0001$ \\
\hline & & $\mathrm{CD}(n=240)$ & & $106(0-494)$ & 1.88 & $0.69-4.08$ & NS \\
\hline & & $\mathrm{AA}(n=84)$ & & & 1.67 & $0.20-6.02$ & NS \\
\hline & & Ectopic $(n=12)$ & & & 13.33 & $0.00-24.59$ & $<0.0001$ \\
\hline & & $\mathrm{AC}(n=29)$ & & & 48.00 & $30.75-71.42$ & $<0.0001$ \\
\hline & & $\mathrm{BNH}(n=11)$ & & & 1.14 & $0.21-6.34$ & NS \\
\hline & & Unknown $(n=10)$ & & & 4.00 & $0.48-14.45$ & 0.0339 \\
\hline
\end{tabular}

${ }^{\mathrm{a} B N H}$, bilateral adrenal nodular hyperplasia (ACTH-independent).

one study (4). They found a significantly elevated SMR of 14 (95\% CI 3.7-40). As all cohorts to date have been small, a more comprehensive collaborative effort will be needed to address the mortality data in this rare etiology.

Ectopic ACTH secretion had, after AC, the next highest mortality profile (SMR 13.33; $P<0.0001$; 95\% CI 0.00-24.59). Only one study (4) has assessed the question of mortality in patients with ectopic CS with discrepant results. Again, because of the rarity and the heterogeneity of this pathology, further studies, based on a larger number of patients, are needed in order to better present the mortality in the ectopic CS patients.

We found that patients with CD have no significantly increased mortality rate (SMR 1.88; 95\% CI 0.694.08). A meta-analysis on the mortality in CD (6), including 688 patients from six studies, revealed similar results - a mean SMR of 1.84 (ranging from 1.0 to 3.8). Others studies $(4,5,11)$ found a significantly elevated mortality rate, perhaps due in part to the longer followup of patients (Table 4).
One of the major contributions of our study is the detailed analysis of the cause of death in patients with CS of different etiologies (Table 3). In the early series, the main causes of death were bacterial infection $(46 \%)$ and cardiac failure $(30 \%)$ (7). Our data showed that the main causes of death are cardiovascular events $(29 \%$ of the cases), followed by infection and septic complications $(12 \%)$ and cerebrovascular disease $(11 \%)$. In our series, the most frequent cause of death in $\mathrm{CD}$, ectopic CS, and AC was cardiovascular diseases, while in AA it was thromboembolic complications. In total, vascular events (cardiovascular and cerebrovascular) were the most frequent cause of death in patients with CS (40\%). An analysis of the mortality rate in the general Bulgarian population reveals that vascular events were the main cause of death $67.5 \%$ in 2010 , $66.3 \%$ in 2000) (12). Patients with CS died from vascular cause at an earlier age - 51.8 years, compared with the general population (64.3 years in 2000 and 63.4 years in 2010). Our data on the cause of mortality in CS are confirmed by previous studies from the last 
10-15 years, although based on very limited numbers of patients and deaths $(5,11,13,14,15)$. Patients with CS had no increased mortality of neoplastic diseases, compared with the general Bulgarian population (6 vs $15.1 \%$ ), most probably due to the shorter duration of life (patients with CS live 20 years less overall than the general population).

One of the limitations of the data on the cause of mortality in our cohort of patients is the high number of patients (16\%) in whom the cause of death could not be clearly identified. Most of these patients died at home or in another hospital without an autopsy protocol. Moreover, because part of the data on patient mortality was provided by the National Statistical Institute (ESGRAON), in some cases the cause of death was given as 'CS' (E24 in ICD-10), 'Osteoporosis' (M80-82 in ICD-10), etc. and therefore we could not obtain a more precise analysis on the immediate cause of death.

The incidence of CS, calculated on the basis of patients treated in our center, was estimated at 1.4/million per year. The Clinical Center of Endocrinology, Medical University of Sofia, is the main tertiary referral center in Bulgaria for treatment of pituitary and adrenal diseases in the country, and sees and manages almost $95 \%$ of patients with CS in Bulgaria. Therefore, the incidence of CS could be slightly underestimated, especially in the case of adrenal cancer, because patients with this disease could be handled by oncology centers. These data coincide with the latest reported data on the incidence of CS $-1.5 /$ million per year (5) and 1.8/million per year (4).

In conclusion, the present data, based on the largest reported heterogeneous cohort of patients with CS, demonstrated significantly increased mortality in CS compared with that of the general population. Although patients with CS have an increased mortality as a whole group, cured patients have no excess mortality. Longer follow up of these cured patients would reveal if this finding would sustain over time. Introduction of new and sophisticated methods for diagnosis and differential diagnosis, advanced techniques for treatment of patients and the possibilities for hormonal substitution, have led to the significant improvement of the patients' management.

\section{Declaration of interest}

The authors declare that there is no conflict of interest that could be perceived as prejudicing the impartiality of the research reported.

\section{Funding}

This work was supported by the Bulgarian Ministry of Education, Youth and Science (grant number DO02-356, 2008).

\section{References}

1 Lindholm J, Juul S, Jørgensen JO, Astrup J, Bjerre P, FeldtRasmussen U, Hagen C, Jørgensen J, Kosteljanetz M, Kristensen L et al. Incidence and late prognosis of Cushing's syndrome: a population-based study. Journal of Clinical Endocrinology and Metabolism 200186 117-123. (doi:10.1210/jc.86.1.117)

2 Etxabe J \& Vazquez JA. Morbidity and mortality in Cushing's disease: an epidemiological approach. Clinical Endocrinology 1994 40 479-484. (doi:10.1111/j.1365-2265.1994.tb02486.x)

3 Ambrosi B, Faglia G \& Multicenter Pituitary Tumor Study Group, Lombardia Region. Epidemiology of pituitary tumors. In Pituitary Adenomas: New Trends in Basic and Clinical Research, vol 5, pp 159-168. Eds G Faglia, P Beck-Peccoz, B Ambrosi, P Travaglini \& A Spada. Amsterdam: Excerpta Medica, 1991.

4 Bolland MJ, Holdaway IM, Berkeley JE, Lim S, Dransfield WJ, Conaglen JV, Croxson MS, Gamble GD, Hunt PJ \& Toomath RJ. Mortality and morbidity in Cushing's syndrome in New Zealand. Clinical Endocrinology 201175 436-442. (doi:10.1111/j.13652265.2011.04124.x)

5 Clayton RN, Raskauskiene D, Reulen RC \& Jones PW. Mortality and morbidity in Cushing's disease over 50 years in Stoke-on-Trent, UK: audit and meta-analysis of literature. Journal of Clinical Endocrinology and Metabolism 201196 632-642. (doi:10.1210/jc.2010-1942)

6 Graversen D, Vestergaard P, Stochholm K, Gravholt CH \& Jørgensen JO. Mortality in Cushing's syndrome: a systematic review and meta-analysis. European Journal of Internal Medicine 201223 278-282. (doi:10.1016/j.ejim.2011.10.013)

7 Plotz CM, Knowlton AI \& Ragan C. The natural history of Cushing's disease. American Journal of Medicine 195213 597-614. (doi:10.1016/0002-9343(52)90027-2)

8 Cushing $\mathrm{H}$. The basophil adenomas of the pituitary body and their clinical manifestations. Bulletin of the Johns Hopkins Hospital 1932 50 137-195.

9 Hammer GD, Tyrrell JB, Lamborn KR, Applebury CB, Hannegan ET, Bell S, Rahl R, Lu A \& Wilson CB. Transsphenoidal microsurgery for Cushing's disease: initial outcomes and longterm results. Journal of Clinical Endocrinology and Metabolism 2004 89 6348-6357. (doi:10.1210/jc.2003-032180)

10 Dekkers OM, Biermasz NR, Pereira AM, Roelfsema F, van Aken MO, Voormolen JH \& Romijn JA. Mortality in patients treated for Cushing's disease is increased, compared with patients treated for non-functioning pituitary macroadenomas. Journal of Clinical Endocrinology and Metabolism 200792 976-981. (doi:10.1210/jc.2006-2112)

11 Hassan-Smith ZK, Sherlock M, Reulen RC, Arlt W, Ayuk J, Toogood AA, Cooper MS, Johnson AP \& Stewart PM. Outcome of Cushing's disease following transsphenoidal surgery in a single center over 20 years. Journal of Clinical Endocrinology and Metabolism 201297 1194-1201. (doi:10.1210/jc.2011-2957)

12 Griva Ch \& Dikova K. Main causes of death in Republic of Bulgaria. National Center for public health and analysis Bulletin 201111. (http://ncphp.government.bg/pechat/164-nac-zdr-danni/бюлет ини/257-смъртн-по-причини.html)

13 Pikkarainen L, Sane T \& Reunanen A. The survival and well-being of patients treated for Cushing's syndrome. Journal of Internal Medicine 1999245 463-468. (doi:10.1046/j.1365-2796.1999.00483.x)

14 Swearingen B, Biller BM, Barker FG II, Katznelson L, Grinspoon S, Klibanski A \& Zervas NT. Long-term mortality after transsphenoidal surgery for Cushing's disease. Annals of Internal Medicine 1999130 821-824. (doi:10.7326/0003-4819-130-10-199905180-00015)

15 Ross EJ \& Linch DC. The clinical response to treatment in adult Cushing's syndrome following remission of hypercortisolaemia. Postgraduate Medical Journal 198561 205-211. (doi:10.1136/ pgmj.61.713.205)

16 Iacobone M, Mantero F, Bosso SM, Lumachi F \& Favia G. Results and long term follow-up after unilateral adrenalectomy for ACTHindependent hypercortisolism in a series of fifty patients. Journal of Endocrinological Investigation 200528 327-332.

Received 16 April 2013

Revised version received 1 August 2013

Accepted 12 August 2013 